\title{
How to modulate chemical structure of polyoxazolines by appropriate functionalization
}

Brieuc Guillerm, Sophie Monge, Vincent Lapinte,* Jean-Jacques Robin

Institut Charles Gerhardt Montpellier UMR5253 CNRS-UM2-ENSCM-UM1 - Equipe Ingénierie et Architectures Macromoléculaires, Université Montpellier II - Bat 17 - cc1702, Place Eugène Bataillon 34095 Montpellier Cedex 5

Corresponding author: Vincent.Lapinte@univ-montp2.fr; Tel: 33-4-67-14-48-32; fax: 33-4-6714-40-28. 


\begin{abstract}
Polyoxazolines (POx) are increasingly studied as polymeric building blocks due to the possibility of affording tunable properties. Additionally, as it was proved that biocompatibility and stealth behavior of POx are similar to that of poly(ethylene glycol) (PEG), it became challenging to develop polyoxazoline-based (co)polymers. Even if POx have a lot of advantages, they also show an important drawback as it is to date impossible to prepare high molecular weight polyoxazolines, with low polydispersity indexes. So, it appears important to judiciously functionalize them. This review covers the multiple ways of functionalization of polyoxazolines. The use of functional initiators, functional terminating agents, and 2-R-2-oxazolines with $\mathrm{R}$ functional side group is detailed. In conclusion, some perspectives on POxfunctionalizations are also reported, with functions permitting selective "click" reactions.
\end{abstract}

Keywords: cationic polymerization; functionalization of polymers; oligomers; ring-opening polymerization 


\section{Introduction}

Polyoxazolines (POx) represents nowadays a valuable type of macromolecules for many reasons. For instance, they are considered as bio-inspired polymers as they are structural isomers of both polyacrylamides, with a pendant amide function, and polypeptides, bearing amide function in the main chain. ${ }^{[1]}$ To date, they were mainly investigated toward biomedical applications ${ }^{[2,3]}$ due to their biocompatibility, biodistribution, blood clearance and protein adsorption. ${ }^{[4-8]}$ Based on their low toxicity, poly(2-oxazolines) are anticipated to be suitable to build antimicrobial materials, when associated with quaternary ammonium salts. They are also employed as drug carriers, for instance. For all these reasons, POx are considered as similar to poly(ethylene glycol) (PEG). It is also important to notice that the latter showed important drawbacks. ${ }^{[9,10]}$ Indeed, it was notably shown that PEG leads to adverse side effects in the body, caused by the polymer itself or by side products which are toxic. Unexpected pharmacokinetic behavior can also occur with PEG-based carriers. These non negligibleproblems led to the development of polyoxazoline derivatives which are today considered as avaluable alternative to PEG.Other important characteristic of POx-based materials is their thermosensitivity as some of them have a lower critical solution temperature (LCST), depending on the R group of the pendant chain. ${ }^{[11]}$ Thermoresponsiveness is often used to build drug carriers, ${ }^{[12]}$ and until now the most studied thermosensitive polymer in the literature is poly(N-isopropylacrylamide) (PNiPAM) as its LCST (around $32{ }^{\circ} \mathrm{C}$ ) is relatively independent of environmental conditions. AsPNiPAM is not proved to be biocompatible,POxmay replace it and,additionally, the LCST value of such polymers can be modulated from 5 to $90{ }^{\circ} \mathrm{C}$ as a function of the $\mathrm{R}$ group of the pendant chain, which is a great advantage.

Well-defined POxsareeasily prepared by cationic ring-opening polymerization (CROP) of cyclic 2-R-2-oxazolines and various properties are obtained as a function of the nature of the $\mathrm{R}$ pendant 
alkyl chain (Me, Et, Pr, etc.). Several teams demonstrated the effect of the R side group on the properties in solution such as solubility in the common solventsand/or water, and the presence of a lower critical solution temperature (LCST).The influenceof the R groupswas also examined in solid state with the determination of mechanical ${ }^{[13,14]}$ and thermal ${ }^{[15-18]}$ properties. Whereas POxsare very promising materials, one of their drawbacks appears to be very restrictive. Indeed, whatever the nature of 2-oxazoline monomer and the initiator, the molecular weight of welldefined POx with low polydispersity index, usable for smart applications, is only limited to about $40 \mathrm{~kg} \cdot \mathrm{mol}^{-1}$ (Table 1). Low molecular weight is an important limitation for the spread development of polyoxazolines in comparison with poly(ethylene glycol) (PEG) competitor (notably in terms of biocompatibility and stealth behavior) which can be prepared with very high molar masses. For this reason, functionalization appears to be the key parameter to overcome this problem. One of the benefits of POx is the possible functionalization of the lateral chain, which is impossible in the case of PEG. Additionally, POx has also the great advantage of being easily converted to polyamines by treatment in acidic medium.In the case of 2-oxazoline bearing alkyl chains, no relation between the nature of the side group and the maximum molecular weight was found. A lot of studies mention transfer reactions as explanation of limited molecular weight but only a few of them investigatesin detailsthis side reaction. Lévy andLitt ${ }^{[19]}$ as well as Kourti, ${ }^{[20]}$ in the particular case of initiator based on metallocene,proposed a monomer transfer reaction based on the abstraction of the $\alpha$-proton of monomer and its transfer on the terminal oxazolinium species of the propagating polymer chain.Schubert et al. illustrated the transfer reaction in the case of 2-ethyl-2-oxazoline using matrix assisted laser desorption/ionization-time of flight (MALDI-Tof) experiments. ${ }^{[21]}$ 


\section{INSERT TABLE 1}

In order to increase the molecular weight and decrease the reaction time, the polymerization of various 2-R-2-oxazolines was achieved by Schubert et al. ${ }^{[22,23]}$ usingmicrowaves. The latter, combined with an increase of the reaction temperature, allowed decreasing the reaction timebut did not lead to higher molecular weights. ${ }^{[24]}$ Indeed, the synthesis of longer well-defined polymer chains in a living way fails as the average molecular weight distributions broaden for polymerization degrees higher than 300.As a consequence, to extend the properties of low molecular weight polyoxazolines, the only solution is to functionalize them with appropriate reactive groups in order to further extend their molar mass by combination with other polymers $^{[25]}$ or to add specific molecules to change some of their properties. For instance, it was proved that antimicrobial activity and hemocompatibilityof telechelicpoly(2-methyloxazoline) is greatly influenced by the nature of the end groups. ${ }^{[26]}$

Functionalization of thePOx chainendsis obtainedby usingfunctional initiators ${ }^{[27]}$ or terminating agents $^{[28]}$ or viathe use of 2-R-2-oxazolines where $\mathrm{R}$ represents a functional pendant group ${ }^{[29]}$ (Figure 1). It is also important to notice that functional groups of initiator or monomer interfere in some caseswith the cationic ring-opening polymerization of $2-\mathrm{R}-2$-oxazoline. ${ }^{[30]}$ This usually detrimentally affectsyields and the control of molecular weight and such problems are minimized by using appropriate protecting groups on initiator ( $\mathrm{P}^{\prime}$ for protecting group in Figure 1), terminating agent or $\mathrm{R}$ pendant group(Pfor protecting group in Figure 1). This protection strategy notably reduces or removes the nucleophilicity and basicity of the reactive sites by steric hindrance and / or electronic effects. Indeed,the cationic character of the polymerization processis 
influenced by all nucleophilic reagents in the reaction medium coming from impurities like water, by-product of the initiator or competingnucleophilic site.

\section{INSERT FIGURE 1}

To develop smart applications, it is important to prepare well-defined polyoxazolines with controlled functionality and molecular weight, and the appropriate functional groups at the chain ends or along the backbone. ${ }^{[31]}$ In this review, we describe functionalized polyoxazolinessuitable for the preparation of well-defined polyoxazoline-based (co)polymers. Functionalizedpolyoxazolinescan be obtained using appropriate functional initiators, terminating agents and pendant chains of 2-R-2-oxazolines. These different molecules are listed and the choice in the functional groups is discussed knowing that some protecting groups are able topush back the limits of incompatibility between functional reactants and CROP process.The functionalization reactions are essentialas it will allow the development of innovative materials based on polyoxazolines. Even if lots of examples are reported in the literature, some interesting perspectives can also be envisaged and will bediscussed at the end of this contribution.

\section{Initiator-based functionalization}

To date, the cationic ring-opening polymerization of 2-oxazolines has been accomplished using many initiators including Lewis acids such as boron trifluoride $\left(\mathrm{BF}_{3}-\mathrm{OEt}_{2}\right)$ (IIIa column of periodic table, 
$2)^{[32]}$ zirconiun/tris(pentafluorophenyl)borate,${ }^{[20]}$ trihalogenobismuthine, ${ }^{[33]}$ and alkyl esters such as tosylates, triflates (VIa column of periodic table, Figure 2) and halides (VIIa column of periodic table, Figure 2). The alkyl halide initiators range from chloride, ${ }^{[34]}$ bromide $^{[35]}$ to iodide ${ }^{[36,37]}$ as well as acetyl halide. ${ }^{[38]}$ The alkyl iodide initiators are mostly converted in situ from chloride ${ }^{[39}$, ${ }^{40]}$ or bromide ${ }^{[41]}$ analogues using $\mathrm{NaI}$ or KI reactants. The simplest iodine initiator is the molecular iodinefor which the mechanism of polymerization has recently been elucidated. ${ }^{[42]}$ Aoi et al.have extensively studied the influence of the nature of the initiator on the mechanism of polymerization which can be ionic and/or covalent. Chemical structure of the initiator also influences the control of the molecular weight. Indeed it was shown that a lack of controlwith the persistence of residual initiator until the end of the polymerization as well as sometimes a latency period at the beginning of the polymerizationis observed with some of the initiators,as demonstrated in the case of 4 -( $p$-toluenesulfonate)methyl-1,3-dioxolan-2-one,${ }^{[43]} 3$-butynyl tosylate,${ }^{[34]}$ tosylate and triflate initiators based on sugar, ${ }^{[44]}$ and macroinitiators such as $\alpha$ methoxy- $\omega$-4-toluene-sulfonate poly(ethylene oxide). ${ }^{[45]}$ An alternative approach to overcome a slow initiation consists in preparing first the propagating species composed of the initiator after reaction with one oxazoline monomer unit. It was widely shown that this oxazolinium compound favors the control of the polymerization related to the precursor initiator. ${ }^{[46]} \alpha$-Functionalized POxwerealso developed. Either the functional group carried by the initiator does not react during the polymerization or it provokes transfer reactions. In the latter case, a protecting step is first required. ${ }^{[30]}$

\section{INSERT FIGURE 2}


The cationic ring-opening polymerization process is compatible with a lot of functionsbased on atoms ofIVa column of the periodic table including carbon and silicon (Figure 2). The most studied initiators have gotalkyl chains of various lengths ${ }^{[22,36,37,47-49]}$ as well as perfluorinated chains. ${ }^{[28,50]}$ The compatibility also exists with unsaturated aliphatic initiators with double ${ }^{[51-53]}$ or triple bonds ${ }^{[34,54,55]}$ even if transfer reactions appeared above $50 \%$ conversion in the latter case. These unsaturated groups have an interest because they can be involved in two types of "click" reaction:thiol-ene coupling (TEC) andcopper catalyzed azide-alkyne cycloaddition (CuAAC) named Huisgen'scycloaddition. These reactions allow the modification of polyoxazolinechain ends ${ }^{[1]}$ and the synthesis ofamphiphilic block copolymers by polymer-polymer coupling. ${ }^{[54]}$ Initiators bearing acetal, oxirane, ${ }^{[56]}$ cyclocarbonate, ${ }^{[43]}$ ester $^{[41,57]}$ and silane ${ }^{[58,59]}$ derivatives also leadto the CROP of oxazolines without any side reactions (Figure 3). Macroinitiators deriving fromcholesteryl ${ }^{[56]}$ and vegetable oils as castor oil, ${ }^{[57]}$ diacylglycerol, ${ }^{[56]} 1,2$-o-diooctadecyl-snglyceryl ${ }^{[48]}$ are employed in the synthesis of amphiphiliccopolymers. The CROP of 2-oxazoline is also compatible with bis-initiators bearing unsaturations like acetylenic groups ${ }^{[55,60]}$ and double bonds. ${ }^{[52,61,62]}$ Multi-functional initiators based on alkyl chains, ${ }^{[61,63,64]}$ aromaticrings with two reactive sites in ortho, meta or para positions ${ }^{[52]}$ or sixreactive sites ${ }^{[65]}$ are used in the elaboration of more complex structures. Other multi-initiators are described such as tetrachloro or iodoinitiators from porphyrine. ${ }^{[66]}$

\section{INSERT FIGURE 3}


Otherwise, some functional initiators need the protection of their competitive reactive sites such as alcohol, thiol, oramine groups (Figure 4) whichcan interfere during the CROP process. These functions are based on heteroatoms belonging to Va and VIa columns of the periodic table (Figure 2). In initiator structure, the amine function is converted into urethane ${ }^{[49]}$ quaternary ammonium salt ${ }^{[26]}$ whereas thiolis transformed into thioether. Alcoholgroupsareconverted into ester groups includingadamantyl which leads to supramolecular network by interactions, ${ }^{[67]}$ or intoacetal or cyclocarbonate groups. Another protecting group of alcohol function is thesilyl ethers like thetert-butyldiphenylsilyl ether. ${ }^{[30]}$ Alcohol groups are also protected into acetate groups in the synthesis of glyco-initiator. ${ }^{[44]}$ Finally, some initiators bearpolymerizable groups such as vinyl ${ }^{[68]}$ andstyrenic ${ }^{[69]}$ groupsin order to further elaborate graft copolymers.

\section{INSERT FIGURE 4}

\section{Terminating agent-based functionalization}

The cationic nature of the oxazoline polymerization and the persistence of the oxazoliniumpropagating species in terminal position of the polymer chain requirea nucleophilic reagent as terminating agent to stop the propagation. Several reactants based on sulfur, oxygen and nitrogen chemistries were already described as illustrated in Figure 5. The terminating agents belong to Va and VIa columns of the periodic table (Figure 2). The most widely used terminating agent is water ${ }^{[47,}{ }^{70,}{ }^{71]}$ or above all its activated corresponding ion: hydroxyl ion in methanolicsodium hydroxide solution ${ }^{[72]}$ or sodium hydrogen carbonate. ${ }^{[73]}$ In this particular case, whatever the activated species, a hydroxy-terminated polyoxazoline is obtained but the 
mechanism of the terminating stage is not the same. Indeed, in the presence of sodium hydrogen carbonate, attack on the 2-position of the oxazolinium ring occurs while attack of nucleophilic reagent takes place on the 5-position of the oxazolinium specie. ${ }^{[74]}$ The other main family deals withamines whichhave an adequate nucleophiliccharacter $(\mathrm{pKa}>10)$ to react with oxazolinium species. The basic nitrogen derivative, ammonia, is successfully used as terminating agent ${ }^{[75]}$ while the primary amines are the most important group, ranging from aliphatic compounds with long chain to obtain amphiphilic copolymers, ${ }^{[76]}$ aniline ${ }^{[51]}$ to various functional primary amines. $^{[69,}$ 77] Secondary cyclic amines as terminating agents are represented bypiperidine ${ }^{[78]}$ piperazine derivatives ${ }^{[39,}$ 79] or morpholine ${ }^{[80]}$ and by bis-functional acyclic amines. ${ }^{[81,82]}$ Even if the tertiary amines such as pyridine, ${ }^{[56]}$ pyrrole ${ }^{[35]}$ and linear amine with long alkyl chain are less reactive than those less substituted, they react as terminating agents for biocide applications. ${ }^{[83]}$ Ainteresting nitrogen terminating agent issodium azide $\left(\mathrm{NaN}_{3}\right)$ which further leadsto Huisgen'scycloaddition to generate amphiphilic copolymers by click reaction. ${ }^{\text {[63, }}$ ${ }^{84]}$ Another approach consists in the use of bis-terminating agent like ethylenediaminein excess to avoid the coupling between two polyoxazoline chains. ${ }^{[26]}$ Functional amine with alcohol group in $\omega$-position is also employed to obtain hydroxy-terminal polyoxazoline without using potassium hydroxide, preventing from the hydrolysis of the ester group of the initiator structure. ${ }^{[67]}$ Another class of terminating agents isbased on sulfur derivatives like sodiumthiolates, ${ }^{[85-88]}$ notably allowing the introduction of carboxylic acids, ${ }^{[88]}$ for instance, or on carboxylic acids and corresponding carboxylate salts such as acrylic acid, ${ }^{[87,}{ }^{89]}$ methacrylic acid, ${ }^{[90-92]}$ maleic acid, ${ }^{[93]}$ glutaric acid, ${ }^{[94]}$ cinnamic acid ${ }^{[95]}$ and terephtalic acid. ${ }^{[90]}$

As explained in the case of functional initiators, functional terminating agents are employed to transformpolyoxazolines in macromonomersfor the further elaboration of grafted copolymers. 
The polyoxazolinemacromonomers belong to styrenic, ${ }^{[39,96]}$ acrylate ${ }^{[89,}$ 97] and methacrylate families. ${ }^{[77,91,92]}$ The last class of terminating agents gathersdifunctionalreagents whichpermitthe increase of the polyoxazolinemolecular weight by a double reaction with central unsaturation coming from the agent. ${ }^{[90,93,94]}$

\section{INSERT FIGURE 5}

\section{Functionalized monomers}

The third method of polyoxazolinefunctionalization corresponds to the use of 2-R-2-oxazoline monomer bearing $\mathrm{R}$ functional pendant group (Figure 6). This possibility of functionalization is a majorbenefit related to poly(ethylene glycol)and offersa supplementary scope of properties in comparison withthe latter.In this purpose,Hoogenboomet al. investigated the feasibility of the preparation of various 2-substituted 2-oxazolines as well as their polymerization. ${ }^{[98]}$ Whatever the $\mathrm{R}$ group, the side chain of the monomer may not react during the CROP process. Consequently, a protecting grouphas to beused when necessary to avoid any side-reaction of $\mathrm{R}$ group with the propagating species. The R pendant groups based on carbon and silicon (IVa column of periodic table, Figure 2) doesnot requiremasking groups. A lot of 2-oxazolines bearing hydrocarbonated pendant groups were developed while few 2-oxazolines with silane pendant chains were synthesized. ${ }^{\left[99,{ }^{100]}\right.}$ The most studied2-oxazoline monomers bearlinear alkyl chain with various lengthsranging from methyl to undecyl groups. ${ }^{[19,71,75,99,101-105]}$ Additionally, the alkyl chain can also be substituted, withiso-propyl, ${ }^{[75]}$ iso-butyl, ${ }^{[103]}$ ter-butyl, ${ }^{[106]}$ neopentyl, ${ }^{[107]}$ ethylheptyl ${ }^{[102]}$ andethylpentyl groups. ${ }^{[108]}$ The influence of $\mathrm{R}$ alkyl group on the polymer solubility, 
mechanical(Young modulus) and thermal properties(glass transition temperature value) properties of the final material has widely been described in the literature. Poly(2-methyl-2oxazoline) and poly(2-ethyl-2-oxazoline) are hydrophilic ${ }^{[16]}$ whereas longer $\mathrm{R}$ groups or aromatic group lead to hydrophobic character, ${ }^{[107]}$ reflecting the importance of $\mathrm{R}$ pendant chain on the solubility.Glass transition temperatures range from 15 to $105^{\circ} \mathrm{C}$ as a function of the $\mathrm{R}$ chain length. ${ }^{[15-18]}$ Otherwise, the Young modulus is only influenced by $\mathrm{R}$ groups containing less than four carbons. ${ }^{[13,14]}$ The impact of the alkyl chain on the behavior of polyoxazoline in solution is also illustrated by the existence of a LCST between 5 and $90{ }^{\circ} \mathrm{C}^{[15,18,109]}$ which is observed for most POx, except for 2-methyl-2-oxazoline.

2-Oxazoline monomers bearing unsaturation are described with single (internal or terminal) ${ }^{[98,103 \text {, }}$ ${ }^{110]}$ or several double bonds such as 2-isopropenyl-2-oxazoline ${ }^{[92]}$ which polymerizes under free,${ }^{[11]}$ controlled (RAFT) radical processes, ${ }^{[112]}$ anionic and cationic polymerizations. ${ }^{[113]} 2-(9-$ Decenyl)-2-oxazoline was modified by thiol-ene coupling in the presence of 2-mercaptoethanol giving polyols for polyurethane formulations. ${ }^{[110]}$ The unsaturationsof soy-based 2-oxazoline monomer were employed to crosslink the core of micelles under UV-irradiation. ${ }^{[114,115]}$ The same strategy is used with tetrathiol in order to elaborate novel photoresist. ${ }^{[16]}$ Alkyne-based oxazolines with one or two unsaturationsare also describedand employed for Huisgen'sCuAACcycloaddition. ${ }^{[79]}$ For instance, Schlaadet al.investigated the crosslinking of block copolymer micelles by thiol-yne reaction. ${ }^{[117]}$ Several 2-oxazolinesbearing cycloaliphatic $\mathrm{R}$ side chains were described with strained cycle, ${ }^{[18]}$ bicycle or tricycle. ${ }^{[98]} 2$-Oxazolines with aromatic R side groups were also synthesized ${ }^{[19]}$ with various substituents ${ }^{[29,98,105,119]}{ }^{\text {including }}$ perfluorogroup. ${ }^{[103,120]}$ Other aromatic systems were investigated with furanyl ${ }^{[103,121]}$ and carbazoyl cycles. 
As illustrated in Figure 2, the mono-halogenated derivatives based on the elements of the VIIa column of the periodic table cannot be considered as pendant chain due to their high reactivity as initiator whichcanmake them react, thus building branched polyoxazolines. Moreover no protecting group exists with easy deprotection protocol for such compounds. From the Va column, only few examples of pendant chain bearing nitrogen or phosphorus atoms are detailed in the literature because of their high reactivity requiring a protecting step with tertbutyloxycarbonyl (Boc) group ${ }^{[98,119]}$ and into phosphoric ester, respectively. ${ }^{[98]}$ Several examples of pendant chains bearing nitrogenated cycle aredescribed with azetidinyl, azepanyl, piperidine, 1-azocanyl, 1-morpholine, 1-pyrrolidinyl ${ }^{[122]}$ and pyrrolidonylethyl. ${ }^{[123]}$ After the hydrocarbonated $\mathrm{R}$ side groups, the oxygenated ones are the most numerous examples in the literature whereasthosebased on sulfurare rare $^{[103]}$ (VIa column of periodic table, Figure 2). Alcohol end group $^{[104]}$ on the pendant chain was investigated even if a protecting group was usually used such as ester ${ }^{[104]}$ or acetal group, ${ }^{[98,}{ }^{123]}$ sometimes cyclic. ${ }^{[124]} \mathrm{An}$ interesting example is the glycooxazolineon which each alcohol group is protected into acetate groups. The last class of $\mathrm{R}$ side groups in 2-oxazoline is represented by polymer chains like polystyrene ${ }^{[15-17]}$ poly(ethylene oxyde $)^{[123]}$ and poly( $\varepsilon$-caprolactone). ${ }^{[125]}$ These 2-oxazolines are employed as macromonomers in the synthesis of graft copolymers.

\section{INSERT FIGURE 6}

\section{Conclusion and Perspectives}


In this review, we described the different ways of functionalization of polyoxazolines using appropriate initiator, terminating agent or viathe $\mathrm{R}$ group of the pendant chain of the $2-\mathrm{R}-2$ oxazoline monomer. It was shown that initiators can bear polyhedral oligomericsilsesquioxane, saccharide, steroid, vegetable oil derivatives, for instance. Terminating agents can notably allow the introduction of a polymerizable groups or sol-gel precursors at the chain end. The wide number of functionalizations of polyoxazolines also comes from $\mathrm{R}$ functional pendant groups in the 2-R-2-oxazoline monomers notably with glucose units, aromatic or fluorescent groups. All these possibilities permit the easy synthesis of very different polyoxazolines with lots of different properties which can be adapted to the targeted application, often in the biomedical field due to the biocompatibility and stealth behavior of POx. Easy functionalization explains the interest brought to polyoxazolines by the researchers who noticed a great contribution of these materials compared to poly(ethylene glycol) which proved these last years to generate some problems for biomedical applications as explained in the introduction of this review. Additionally, in the case of PEG, functional groups cannot be introduced so easily. On the reverse,functionalizations of POx lead to further reactivity and permit the building of more complex macromolecular architectures by polymer-polymer coupling or by using polyoxazoline derivatives as macroinitiators.

Among all possibilities of functionalization of $\mathrm{POx}$, selective and orthogonal reactions named "click" reactions appear to be of interest and were already successfully employed in macromolecular chemistry. ${ }^{[126]}$ More precisely, POxfunctionalizations have already been described in the literature usingthiol-ene ${ }^{[127]}$ andthiol-yne ${ }^{[117]}$ reactions, and the Huisgen'scycloaddition catalyzed by copper (CuAAC) reaction. ${ }^{[7,}{ }^{128]}$ In such cases, polyoxazolinesbear double, triple bonds, or azido groups (Figure 7). 


\section{INSERT FIGURE 7}

Another example involving POx deals with a multifunctional copoly(2-oxazoline) containing $\alpha$ -

anthracene and $\omega$-azide termini as well as pendant alkene group in the side chain (Figure 8). ${ }^{[128]}$ In that case, three different "click" reactionsare achieved: (i) azide-alkyne cycloadditon, (ii) Diels-Alder reaction, and finally (iii) thiol-ene reaction. This example is very interesting as it shows that multi functional polyoxazolines can be prepared leading to complex chemical structures with a very good control over the molecular weight of the polymer.

\section{INSERT FIGURE 8}

From works already described in the literature, some perspectives for the development of new functionalized polyoxazolines can be considered, based on "click" reactions (Figure 9). Indeed, from multi-functional POx just described, it is obvious that Diels-Alder "click" must be studied, taking into account previous work reported by Saegusa ${ }^{[129]}$ and Stevens. ${ }^{[130]}$ The great interest of the Diels-Alder reaction is that it is reversible as a function of the temperature. So,thermoreversible Diels-Alder reaction could lead to the release ofpolyoxazoline bearing unsaturation in terminal or pendant groups. ${ }^{[131]}$ Thus, new polyoxazolines bearing diene have to be prepared to react with a dienophile. On the other hand,POxdienophile has already been synthesized and could react with diene. Another possibility consists in developing "pentafluoro" clicking, as already mentioned in the literature for other kinds of polymers. ${ }^{[132]}$ This reaction 
corresponds to the "clicking" of thiol with pentafluoro groups, the latter being introduced via the initiator of in the pendant chain of the oxazoline monomer (Figure 9).

\section{INSERT FIGURE 9}

These perspectives demonstrate that the synthesis of various polyoxazoline-based (co)polymers is still possible, by using already prepared polyoxazolines or new ones with useful functionalities. These new structures might lead to innovative materials that could be employed for smart applications, notably for the biomedical field which requires a good control over the molar mass and the molecular weight distribution, and also appropriate functionalities. 


\section{Figure Captions}

Table 1. Limited molecular weights of polymer chains for various oxazoline monomers allowing the obtaining of well-defined polyoxazolines with low polydispersity indexes.

Figure 1. General synthetic considerations for the synthesis of functionalized polyoxazolines (Ini: initiator, $\mathrm{T}$ : terminating agent, $\mathrm{P}$ and $\mathrm{P}$ ': protecting groups).

Figure 2.The terminating agents and the pendant chainsof oxazolinesbearing various elements of the periodic table as well as the nature of the initiators.

Figure 3. Functionalized initiators for the cationic ring-opening polymerization of 2-R-2oxazolines.

Figure 4. Initiators bearing additional protected and unprotected groups.

Figure 5. Terminating agents for the cationic ring-opening polymerization of 2-R-2-oxazolines.

Figure 6.R side groups of 2-R-2-oxazoline allowing the functionalization of POx pendant chains.

Figure 7.Polyoxazolines bearing functional groups allowing "click chemistry" reactions (All chemical structures were employed in "click" reactions except azido-containing polyoxazoline with aromatic ring, as mentioned).

Figure 8. Chemical structure of multi-functionalized poly(2-oxazoline) allowing the incorporation of residues by three orthogonal "click" reactions (Diels-Alder, thiol-ene reactions, and azide-alkyne cycloaddition. ${ }^{[128]}$ 
Figure 9. Perspectives concerning the synthesis of functionalized polyoxazolines from precursors bearing appropriate functionality. 
Table 1. Limited molecular weightsof polymer chainsfor various oxazoline monomers allowing the obtaining of well-defined polyoxazolines with low polydispersity indexes.

\begin{tabular}{|c|c|c|c|}
\hline $\mathbf{R}$ & $\mathbf{D P}_{\mathrm{n}, \mathrm{exp}}$ & $\begin{array}{c}M_{n, \max } \\
\left(\mathrm{g} \cdot \mathrm{mol}^{-1}\right)\end{array}$ & $\boldsymbol{\oplus}$ \\
\hline $\mathbf{M e}^{[83]}$ & 149 & 13000 & 1.04 \\
\hline$E t^{[38,133]}$ & 404 & 40000 & 1.20 \\
\hline $\operatorname{Pr}^{[134]}$ & 106 & 12000 & 1.04 \\
\hline$i \operatorname{Pr}^{[75]}$ & 86 & 10000 & 1.02 \\
\hline Bu & & 13000 & \\
\hline Pent & & 14000 & \\
\hline Hex & $100^{[14]}$ & 15000 & 1.20 \\
\hline Hept & & 17000 & \\
\hline Non & & 20000 & \\
\hline $\mathbf{P h}^{[73]}$ & 51 & 8000 & 1.31 \\
\hline
\end{tabular}

$Ð$ : polydispersity index. 
Figure1.General synthetic considerations for the synthesis of functionalizedpolyoxazolines (Ini: initiator, T: terminating agent, $\mathrm{P}$ and P': protecting groups). 


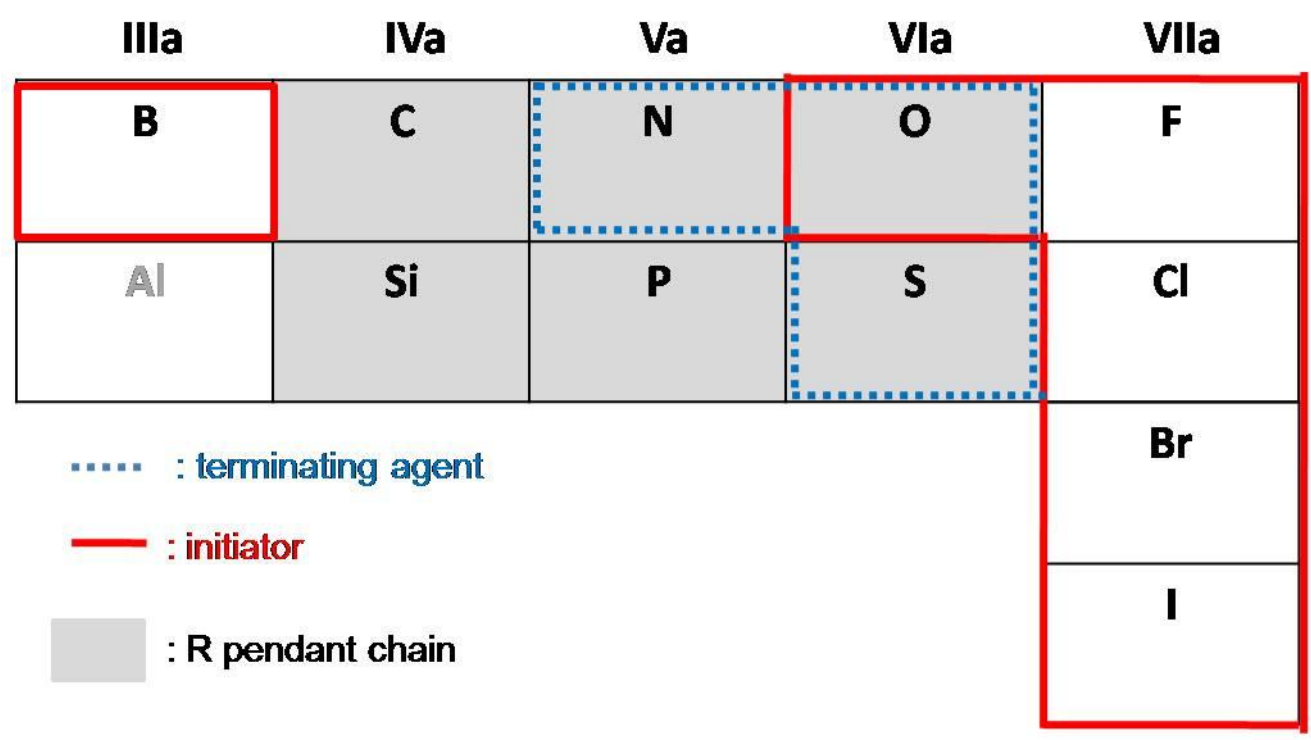

Figure 2.The terminating agents and the pendant chainsof oxazolinesbearing various elements of the periodic table as well as the nature of the initiators. 
Figure 3. Functionalized initiators for the cationic ring-opening polymerization of 2-R-2oxazolines. 
Figure4.Initiatorsbearing additional protected and unprotected groups. 


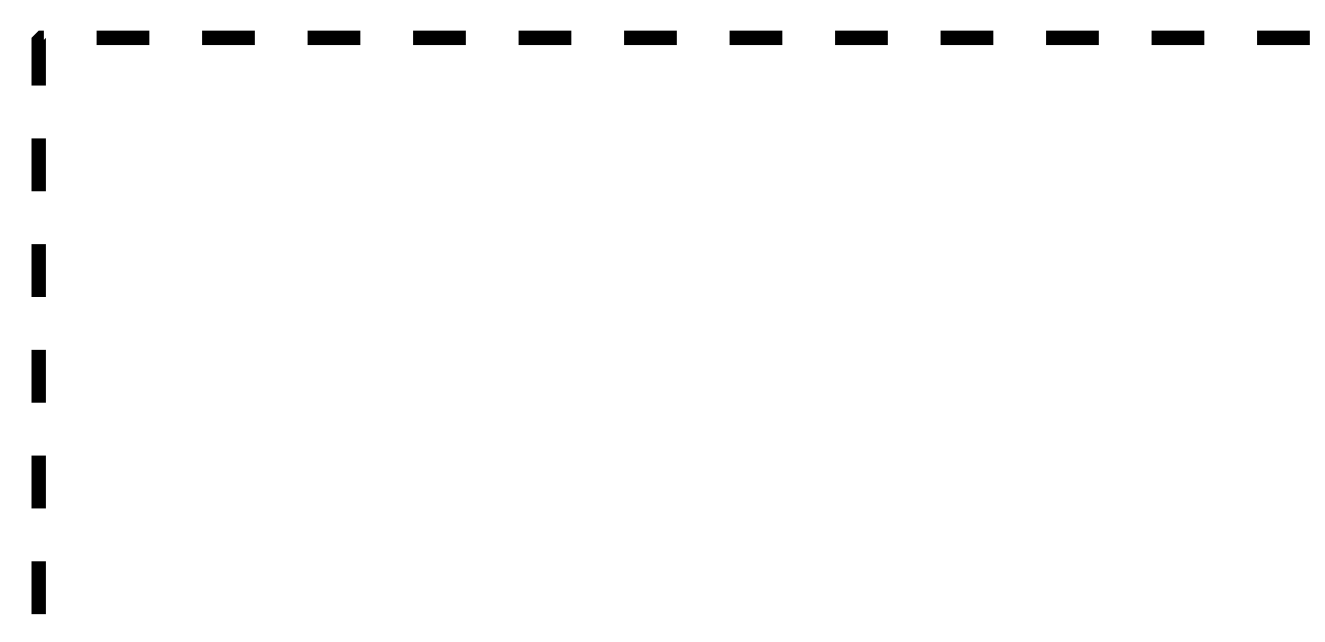

Figure 5. Terminating agents for the cationic ring-opening polymerization of 2-R-2-oxazolines. 
Figure 6.R sidegroups of2-R-2-oxazoline allowing the functionalization of POx pendant chains. 
Figure 7.Polyoxazolines bearing functional groups allowing "click chemistry" reactions (All chemical structures were employed in "click" reactions exceptazido-containing polyoxazoline with aromatic ring, as mentioned). 
Figure 8. Chemical structure of multi-functionalized poly(2-oxazoline) allowing the incorporation of residues by three orthogonal "click" reactions (Diels-Alder, thiol-ene reactions, and azidealkyne cycloaddition. ${ }^{[128]}$ 


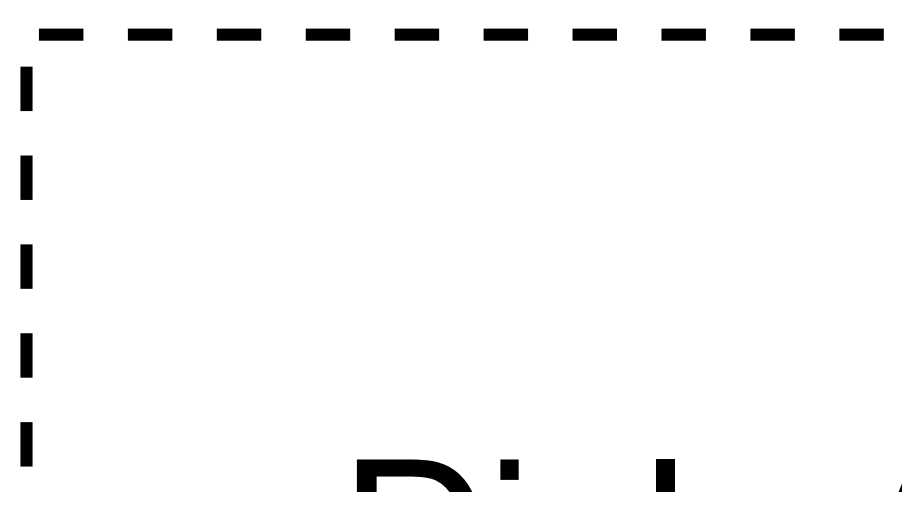

Figure 9. Perspectives concerning the synthesis of functionalized polyoxazolines from precursors bearing appropriate functionality. 


\section{References}

[1] H. Schlaad, C. Diehl, A. Gress, M. Meyer, A. L. Demirel, Y. Nur, A. Bertin, Macromolecular Rapid Communications2010, 31, 511.

[2] R. Hoogenboom, Angewandte Chemie International Edition2009, 48, 7978.

[3] R. Hoogenboom, H. Schlaad, Polymers2011, 3, 467.

[4] M. Bauer, C. Lautenschlaeger, K. Kempe, L. Tauhardt, U. S. Schubert, F. D., Macromolecular Bioscience2012. (doi: 10.1002/mabi.201200026)

[5] F. C. Gaertner, R. Luxenhofer, B. Blechert, R. Jordan, M. Essler, Journal of Controlled Release2007, 119, 291.

[6] P. Goddard, L. E. Hutchinson, J. Brown, L. J. Brookman, Journal of Controlled and Release1989, 10, 5.

[7] R. Konradi, B. Pidhatika, A. Muhlebach, M. Textort, Langmuir2008, 24, 613.

[8] R. Luxenhofer, G. Sahay, A. Schulz, D. Alakhova, T. K. Bronich, R. Jordan, A. V. Kabanov, Journal of Controlled Release2011, 153, 73.

[9] K. Knop, R. Hoogenboom, D. Fischer, U. S. Schubert, Angewandte Chemie International Edition 2010, 49, 6288.

[10] M. Barz, R. Luxenhofer, R. Zentel, M. J. Vicent, Polymer Chemistry2011, 2, 1900.

[11] C. Diehl, H. Schlaad, Macromolecular Bioscience2009, 9, 157.

[12] M. Talelli, W. E. Hennink, Nanomedicine2011, 6, 1245.

[13] M. W. M. Fijten, J. M. Kranenburg, H. M. L. Thijs, R. M. Paulus, B. M. Van Lankvelt, J. De Hullu, M. Springintveld, D. J. G. Thielen, C. A. Tweedie, R. Hoogenboom, K. J. Van Vliet, U. S. Schubert, Macromolecules2007, 40, 5879.

[14] E. F. J. Rettler, J. M. Kranenburg, H. M. L. Lambermont-Thijs, R. Hoogenboom, U. S. Schubert, Macromolecular Chemistry and Physics2010, 211, 2443.

[15] M. Baumert, J. Zimmermann, J. Scherble, R. Mülhaupt, J. Kressler, Macromolecules1999, 32, 2503.

[16] H. Malz, H. Komber, D. Voigt, I. Hopfe, J. Pionteck, Macromolecular Chemistry and Physics1999, 200, 642.

[17] H. Malz, J. Pionteck, P. Pötschke, H. Komber, D. Voigt, J. Lustoň, F. Böhme, Macromolecular Chemistry and Physics 2001, 202, 2148.

[18] I. H. Saegusa T., Fujii H., Polymer Journal1973, 4, 87.

[19] M. Litt, A. Levy, J. Herz, Journal of Macromolecular Science Part A: Pure and Applied Chemistry 1975, 9, 703

[20] M. E. Kourti, G. C. Vougioukalakis, N. Hadjichristidis, M. Pitsikalis, Journal of Polymer Science Part A: Polymer Chemistry2011, 49, 2520.

[21] A. Baumgaertel, C. Weber, K. Knop, A. Crecelius, U. S. Schubert, Rapid Communications in Mass Spectrometry2009, 23, 756.

[22] F. Wiesbrock, R. Hoogenboom, M. A. M. Leenen, M. A. R. Meier, U. S. Schubert, Macromolecules 2005, 38, 5025.

[23] K. Kempe, C. R. Becer, U. S. Schubert, Macromolecules2011, 44, 5825.

[24] F. Wiesbrock, R. Hoogenboom, C. H. Abeln, U. S. Schubert, Macromolecular Rapid Communications2004, 25, 1895.

[25] C. H. Wang, G. H. Hsiue, Biomacromolecules2003, 4, 1487.

[26] C. P. Fik, C. Krumm, C. Muennig, T. I. Baur, U. Salz, T. Bock, J. C. Tiller, Biomacromolecules2012, 13, 165. 
[27] M. G. Alemseghed, J. Servello, N. Hundt, P. Sista, M. C. Biewer, M. C. Stefan, Macromolecular Chemistry and Physics 2010, 211, 1291.

[28] R. Weberskirch, J. Preuschen, H. W. Spiess, O. Nuyken, Macromolecular Chemistry and Physics2000, 201, 995.

[29] W. H. Binder, H. Gruber, Macromolecular Chemistry and Physics2000, 201, 949.

[30] M. Reif, R. Jordan, Macromolecular Chemistry and Physics2011, 212, 1815.

[31] L. Buruaga, A. Gonzalez, J. J. Iruin, Journal of Materials Science2009, 44, 3186.

[32] T. Saegusa, H. Ikeda, H. Fujii, Polymer Journal1972, 3, 176.

[33] P. Buzin, G. Schwarz, H. R. Kricheldorf, Journal of Polymer Science Part A: Polymer Chemistry2008, 46, 4777.

[34] M. W. M. Fijten, C. Haensch, B. M. Van Lankvelt, R. Hoogenboom, U. S. Schubert, Macromolecular Chemistry and Physics 2008, 209, 1887.

[35] A. Cirpan, S. Alkan, L. Toppare, G. David, Y. Yagci, European Polymer Journal2001, 37, 2225.

[36] T. Saegusa, H. Ikeda, Macromolecules1973, 6, 808.

[37] G. Volet, V. Chanthavong, V. Wintgens, C. Amiel, Macromolecules2005, 38, 5190.

[38] R. M. Paulus, C. R. Becer, R. Hoogenboom, U. S. Schubert, Macromolecular Chemistry and Physics2008, 209, 794.

[39] J. C. Rueda, H. Komber, J. C. Cedrón, B. Voit, G. Shevtsova, Macromolecular Chemistry and Physics 2003, 204, 947.

[40] R. Weberskirch, R. Hettich, O. Nuyken, D. Schmaljohann, B. Voit, Macromolecular Chemistry and Physics1999, 200, 863.

[41] S. Zalipsky, C. B. Hansen, J. M. Oaks, T. M. Allen, Journal of Pharmaceutical Sciences1996, 85, 133.

[42] B. Guillerm, S. Monge, V. Lapinte, J. J. Robin, Macromolecules2010, 43, 5964.

[43] C. Giardi, V. Lapinte, F. Nielloud, J. M. Devoisselle, J. J. Robin, Journal of Polymer Science Part A: Polymer Chemistry2010, 48, 4027.

[44] C. Weber, J. A. Czaplewska, A. Baumgaertel, E. Altuntas, M. Gottschaldt, R. Hoogenboom, U. S. Schubert, Macromolecules 2012, 45, 46.

[45] B. Brissault, C. Guis, H. Cheradame, European Polymer Journal2002, 38, 219.

[46] S. Cesana, J. Auernheimer, R. Jordan, H. Kessler, O. Nuyken, Macromolecular Chemistry and Physics 2006, 207, 183.

[47] R. Hoogenboom, M. W. M. Fijten, U. S. Schubert, Journal of Polymer Science Part A: Polymer Chemistry2004, 42, 1830.

[48] R. Jordan, K. Martin, H. J. Räder, K. K. Unger, Macromolecules2001, 34, 8858.

[49] C. J. Waschinski, V. Herdes, F. Schueler, J. C. Tiller, Macromolecular Bioscience2005, 5, 149.

[50] V. Lapinte, J. J. Robin, G. Merenna, C. Colin; FR 0900559, 2010.

[51] Y. Chujo, E. Ihara, H. Ihara, T. Saegusa, Macromolecules1989, 22, 2040.

[52] S. Kobayashi, H. Uyama, Y. Narita, J. Ishiyama, Macromolecules1992, 25, 3232.

[53] P. D. Trivedi, D. N. Schulz, Polymer Bulletin1980, 3, 37.

[54] B. Guillerm, V. Darcos, V. Lapinte, S. Monge, J. Coudane, J.-J. Robin, Chemical Communications2012, 48,2879-2881.

[55] S. Kobayashi, H. Uyama, T. Mori, Y. Narita, Chemistry Letters1991, 20, 1771.

[56] M. Einzmann, W. H. Binder, Journal of Polymer Science Part A: Polymer Chemistry2001, $39,2821$. 
[57] C. Giardi, V. Lapinte, C. Charnay, J. J. Robin, Reactive and Functional Polymers2009, 69, 643.

[58] J. S. Hrkach, K. Matyjaszewski, Macromolecules1992, 25, 2070.

[59] K. Pielichowski, J. Njuguna, B. Janowski, J. Pielichowski, "Polyhedral Oligomeric Silsesquioxanes (POSS)-Containing Nanohybrid Polymers", in Supramolecular Polymers Polymeric Betains Oligomers, Springer Berlin / Heidelberg, 2006, p. 225.

[60] M. Einzmann, W. H. Binder, Macromolecular Symposia2002, 181, 57.

[61] S. Kobayashi, H. Uyama, Y. Narita, Macromolecules1990, 23, 353.

[62] S. Kobayashi, H. Uyama, Y. Narita, Die Makromolekulare Chemie Rapid Communications 1992, 13, 337.

[63] G. Volet, T. X. Lav, J. Babinot, C. Amiel, Macromolecular Chemistry and Physics2011, $212,118$.

[64] R. Luxenhofer, M. Bezen, R. Jordan, Macromolecular Rapid Communications2008, 29, 1509.

[65] R. H. Jin, Journal of Materials Chemistry2003, 13, 672.

[66] R. H. Jin, Journal of Materials Chemistry2004, 14, 320.

[67] J. Stadermann, H. Komber, M. Erber, F. Däbritz, H. Ritter, B. Voit, Macromolecules2011, 44,3250 .

[68] H. Uyama, S. Kobayashi, Macromolecules1991, 24, 614.

[69] S. Kobayashi, M. Kaku, S. Sawada, T. Saegusa, Polymer Bulletin1985, 13, 447.

[70] O. Nuyken, G. Maier, A. Gross, H. Fischer, Macromolecular Chemistry and Physics1996, $197,83$.

[71] S. Kobayashi, E. Masuda, S. Shoda, Y. Shimano, Macromolecules1989, 22, 2878.

[72] K. Aoi, M. Okada, Progress in Polymer Science 1996, 21, 151.

[73] R. Hoogenboom, M. W. M. Fijten, U. S. Schubert, Macromolecular Rapid Communications2004, 25, 339.

[74] P. Dubois, O. Coulembier, J. M. Raquez, Handbook of Ring-Opening Polymerization2009.

[75] J. S. Park, Y. Akiyama, F. M. Winnik, K. Kataoka, Macromolecules2004, 37, 6786.

[76] G. Volet, A. C. L. Deschamps, C. Amiel, Journal of Polymer Science Part A: Polymer Chemistry2010, 48, 2477.

[77] A. Förtig, R. Jordan, K. Graf, G. Schiavon, O. Purrucker, M. Tanaka, Macromolecular Symposia2004, 210, 329.

[78] R. Hoogenboom, M. W. M. Fijten, M. A. R. Meier, U. S. Schubert, Macromolecular Rapid Communications2003, 24, 92.

[79] R. Luxenhofer, R. Jordan, Macromolecules2006, 39, 3509.

[80] P. Van Caeter, E. Goethals, V. Gancheva, R. Velichkova, Polymer Bulletin1997, 39, 589.

[81] M. Adeli, Z. Zarnegar, R. Kabiri, European Polymer Journal2008, 44, 1921.

[82] Y. Chujo, E. Ihara, S. Kure, T. Saegusa, Macromolecules1993, 26, 5681.

[83] C. J. Waschinski, J. C. Tiller, Biomacromolecules2004, 6, 235.

[84] C. Guis, H. Cheradame, European Polymer Journal2000, 36, 2581.

[85] R. L. L. Loontjens T., Designed Monomers and Polymers1999, 2, 217.

[86] PCT/US2009/050286,2010.

[87] T. X. Viegas, M. D. Bentley, J. M. Harris, Z. Fang, K. Yoon, B. Dizman, R. Weimer, A. Mero, G. Pasut, F. M. Veronese, Bioconjugate Chemistry2011, 22, 976.

[88] A. Mero, Z. Fang, G. Pasut, F. M. Veronese, T. X. Viegas, Journal of Controlled Release2012, 159, 353. 
[89] D. Christova, R. Velichkova, E. J. Goethals, Macromolecular Rapid Communications1997, $18,1067$.

[90] M. Miyamoto, K. Naka, M. Tokumizu, T. Saegusa, Macromolecules1989, 22, 1604.

[91] C. Weber, A. Krieg, R. M. Paulus, H. M. L. Lambermont-Thijs, C. R. Becer, R. Hoogenboom, U. S. Schubert, Macromolecular Symposia2011, 308, 17.

[92] C. Weber, T. Neuwirth, K. Kempe, B. Ozkahraman, E. Tamahkar, H. Mert, C. R. Becer, U. S. Schubert, Macromolecules2012, 45, 20.

[93] G. David, V. Alupei, B. C. Simionescu, European Polymer Journal2001, 37, 1353.

[94] M. C. Woodle, C. M. Engbers, S. Zalipsky, Bioconjugate Chemistry1994, 5, 493.

[95] G. David, A. Ioanid, Journal of Applied Polymer Science2001, 80, 2191.

[96] A. Groß, G. Maier, O. Nuyken, Macromolecular Chemistry and Physics1996, 197, 2811.

[97] C. Weber, C. R. Becer, W. Guenther, R. Hoogenboom, U. S. Schubert, Macromolecules 2010, 43, 160.

[98] K. Kempe, M. Lobert, R. Hoogenboom, U. S. Schubert, Journal of Combinatorial Chemistry2009, 11, 274.

[99] G. Cai, M. H. Litt, Journal of Polymer Science Part A: Polymer Chemistry1992, 30, 649.

[100] G. Cai, M. H. Litt, Macromolecules1992, 25, 2277.

[101] N. Adams, U. S. Schubert, Advanced Drug Delivery Reviews2007, 59, 1504.

[102] K. Kempe, S. Jacobs, H. M. L. Lambermont-Thijs, M. M. W. M. Fijten, R. Hoogenboom, U. S. Schubert, Macromolecules 2010, 43, 4098.

[103] K. Kempe, M. Lobert, R. Hoogenboom, U. S. Schubert, Journal of Polymer Science Part A: Polymer Chemistry2009, 47, 3829.

[104] A. Levy, M. Litt, Journal of Polymer Science Part A: Polymer Chemistry1968, 6, 1883.

[105] P. Persigehl, R. Jordan, O. Nuyken, Macromolecules2000, 33, 6977.

[106] K. Aoi, A. Takasu, M. Okada, T. Imae, Macromolecular Chemistry and Physics1999, 200, 1112.

[107] M. Miyamoto, K. Aoi, M. Morimoto, Y. Chujo, T. Saegusa, Macromolecules1992, 25, 5878.

[108] E. Altuntaş, K. Kempe, A. Crecelius, R. Hoogenboom, U. S. Schubert, Macromolecular Chemistry and Physics2010, 211, 2312.

[109] R. Luxenhofer, A. Schulz, C. Roques, S. Li, T. K. Bronich, E. V. Batrakova, R. Jordan, A. V. Kabanov, Biomaterials2010, 31, 4972.

[110] E. Del Rio, G. Lligadas, J. C. Ronda, M. Galià, V. Cádiz, Journal of Polymer Science Part A: Polymer Chemistry2011, 49, 3069.

[111] J. M. Havard, M. Yoshida, D. Pasini, N. Vladimirov, J. M. J. Frechet, D. R. Medeiros, K. Patterson, S. Yamada, C. G. Willson, J. D. Byers, Journal of Polymer Science Part A: Polymer Chemistry1999, 37, 1225.

[112] N. Zhang, S. Huber, A. Schulz, R. Luxenhofer, R. Jordan, Macromolecules2009, 42, 2215.

[113] T. Kagiya, T. Matsuda, K. Zushi, Journal of Macromolecular Science Part A: Pure and Applied Chemistry1972, A 6, 1349.

[114] R. Hoogenboom, U. S. Schubert, Green Chemistry2006, 8, 895.

[115] R. Hoogenboom, European Journal of Lipid Science and Technology2011, 113, 59.

[116] V. Schenk, L. Ellmaier, E. Rossegger, M. Edler, T. Griesser, G. Weidinger, F. Wiesbrock, Macromolecular Rapid Communications2012, 33, 396.

[117] N. ten Brummelhuis, H. Schlaad, Polymer Chemistry2011, 2, 1180.

[118] M. M. Bloksma, C. Weber, I. Y. Perevyazko, A. Kuse, A. Baumgärtel, A. Vollrath, R. Hoogenboom, U. S. Schubert, Macromolecules2011, 44, 4057. 
[119] S. Cesana, A. Kurek, M. A. Baur, J. Auernheimer, O. Nuyken, Macromolecular Rapid Communications 2007, 28, 608.

[120] M. Lobert, H. M. L. Thijs, T. Erdmenger, R. Eckardt, C. Ulbricht, R. Hoogenboom, U. S. Schubert, Chemistry - A European Journal2008, 14, 10396.

[121] B. R. Hsieh, M. H. Litt, Macromolecules1986, 19, 516.

[122] M. Miyamoto, M. Shimakura, K. Tsutsui, K. Hasegawa, K. Aoi, S. Yamaga, T. Saegusa, Macromolecules1993, 26, 7116.

[123] K. Lüdtke, R. Jordan, P. Hommes, O. Nuyken, C. A. Naumann, Macromolecular Bioscience 2005, 5, 384.

[124] C. Taubmann, R. Luxenhofer, S. Cesana, R. Jordan, Macromolecular Bioscience2005, 5, 603.

[125] O. Glaied, C. Delaite, G. Hurtrez, M. Joubert, P. Dumas, Journal of Polymer Science Part A: Polymer Chemistry2005, 43, 2440.

[126] W. H. Binder, R. Sachsenhofer, Macromolecular Rapid Communications2007, 28, 15.

[127] A. B. Lowe, C. E. Hoyle, C. N. Bowman, Journal of Materials Chemistry2010, 20, 4745.

[128] K. Kempe, R. Hoogenboom, M. Jaeger, U. S. Schubert, Macromolecules2011, 44, 6424.

[129] Y. Chujo, K. Sada, T. Saegusa, Macromolecules1990, 23, 2636.

[130] S. A. Canary, M. P. Stevens, Journal of Polymer Science Part A: Polymer Chemistry1992, $30,1755$.

[131] J. A. Syrett, C. R. Becer, D. M. Haddleton, Polymer Chemistry2010, 1, 978.

[132] C. R. Becer, K. Babiuch, D. Pilz, S. Hornig, T. Heinze, M. Gottschaldt, U. S. Schubert, Macromolecules2009, 42, 2387.

[133] Q. Liu, M. Konas, J. S. Riffle, Macromolecules1993, 26, 5572.

[134] J. S. Park, K. Kataoka, Macromolecules 2007, 40, 3599. 


\section{Table of Contents}

\section{How to modulate chemical structure of polyoxazolines by appropriate functionalization}

Brieuc Guillerm, Sophie Monge, Vincent Lapinte, ${ }^{*}$ Jean-Jacques Robin

Poly(2-oxazoline)s are widely employed as polymeric building block for the obtaining of well defined macromolecular architecturesfor smart applications. As a consequence, the functionalization of such derivatives is of great interest. The versatility and the diversity of the latterusing functional initiators, terminating agents and $\mathrm{R}$ pendant chains of the monomersare highlighted in this review.

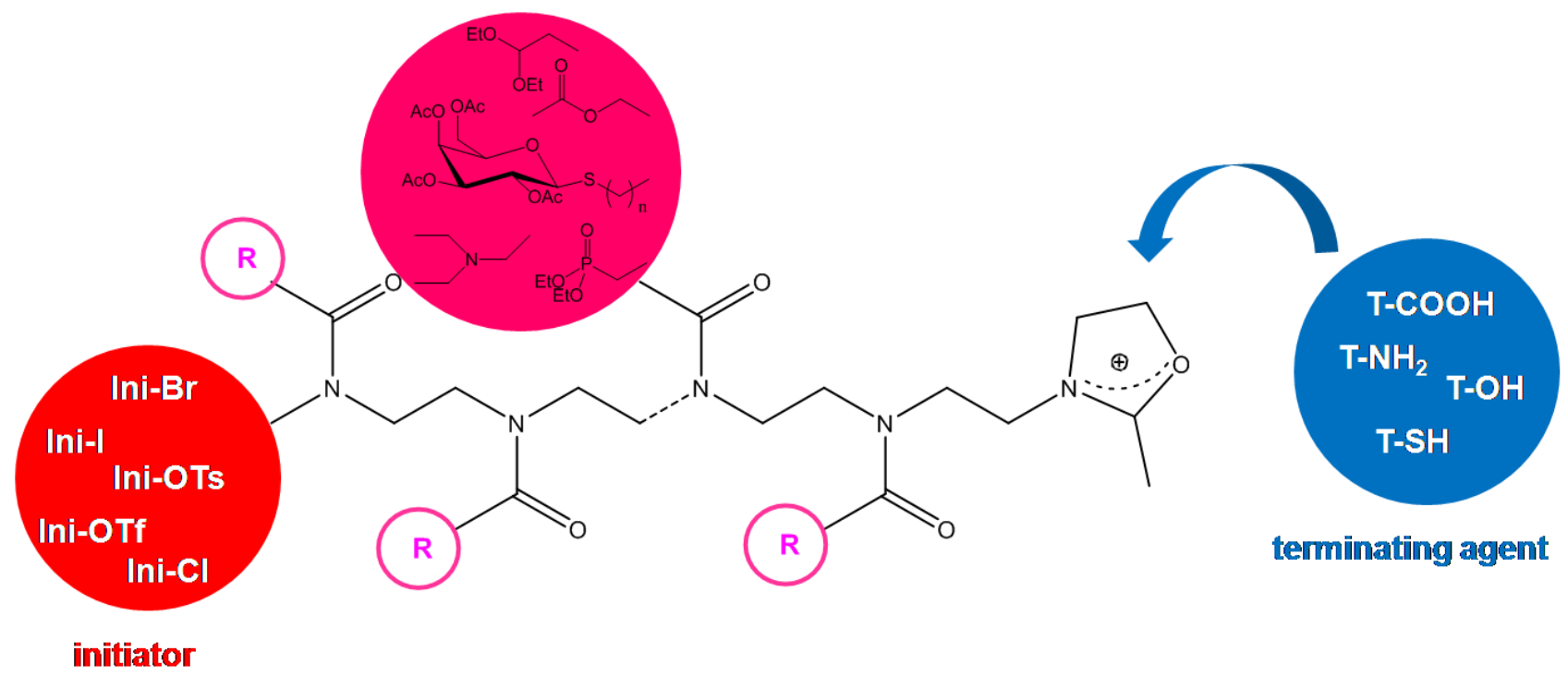




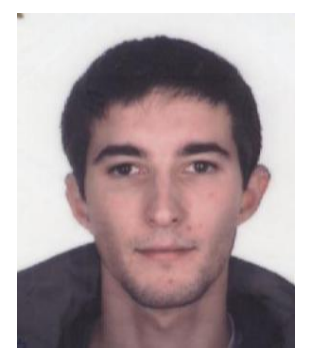

BrieucGuillerm (born in 1983 in Landerneau) obtained his Ph.D. degree in 2011 at the University of Montpellier 2 (France), in the group of Prof. Jean-Jacques Robin at the "Institut Charles Gerhardt de Montpellier", under the supervision of Dr. Sophie Monge and Dr. Vincent Lapinte. His work dealt with the synthesis and physical chemistry study of amphiphilic copolymers based on polyoxazoline. He is currently a post doctoral researcher in the group of Prof. Philippe Dubois at the University of Mons (Belgium). His general research interests are now the synthesis of poly( $\varepsilon$-caprolactone) and polylactide, especially using organocatalyst.

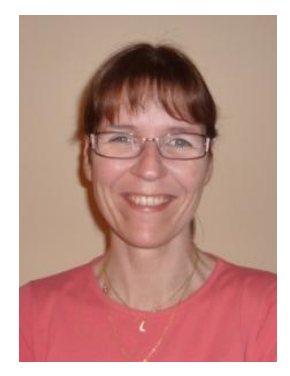

Sophie Monge (born in 1975 in Toulon) obtained her Ph.D. degree in 2000 at the University of Montpellier 2 (France), working in the laboratory of Prof. André A. Pavia and Prof. J. P. Roque on the synthesis of iodine-labeled telomers containing 2-nitroimidazole for the detection of hypoxic tissues and tumors. Then, she was awarded a Marie Curie fellowship for a post-doctoral position (two years) in the group of Prof. Dave Haddleton at the University of Warwick (UK), working on atom transfer radical polymerization. She joined in 2002 the laboratory of Prof. J. J. Robin in the "Institut Charles Gerhardt de Montpellier". Her research interest mainly focuses on the synthesis of well-defined (co)polymers with stimuli-responsive properties, and with polymers bearing heteroatoms. 


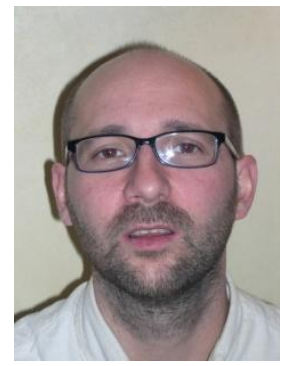

Vincent Lapinte (born in 1973 in Tours) obtained his Ph.D. degree in 2003 at the University of Maine (France), working in the laboratory of Prof. Laurent Fontaine on the synthesis and the design of functionalized polymers by ring-opening metathesis polymerization. Then, he obtained a postdoctoral position on the synthesis of polymers based on nitrogen-rich heterocycles in the laboratory of Dr. D. Poullain (CEA, Le Ripault), with the collaboration of Prof. F. Fontaine and Prof J.-F. Pilard. He joined in 2004 the laboratory of Prof. J. J. Robin in the "Institut Charles Gerhardt de Montpellier". His research interest mainly covers the chemical modification and the use of vegetable oils in polymer field as well as the polyoxazolines.

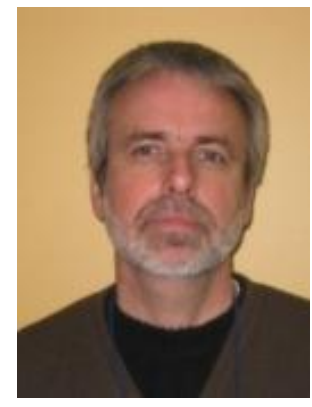

Jean-Jacques is a full professor of Polymer Chemistry at the University of Montpellier 2, (France). He received his Ph.D. degree in 1985 from the same university. His area of expertise is the synthesis of graft copolymers and the chemical recycling of polymers. He is currently leading the "Ingénierieet Architectures Macromoléculaires" laboratory of the "Institut Charles Gerhardt de Montpellier". 